\title{
Two mutations in the HR2 region of Newcastle disease virus fusion protein with a cleavage motif "RRQRRL" are critical for fusogenic activity
}

Yanhong Wang, Youkun Bi, Wanqi Yu, Ning Wei, Wenbin Wang, Qiaolin Wei, Xinglong Wang, Shuxia Zhang, Zengqi Yang ${ }^{*}$ and Sa Xiao*

\begin{abstract}
Background: Newcastle disease virus (NDV) causes severe diseases in avian species. Its fusion protein cleavage site (FCS) is a major contributor to virulence and membrane fusion. Previous studies showed that a change from phenylalanine $(F)$ to lysine $(L)$ at position 117 of the virulent strain fusion protein, which has the polybasic amino acid FCs motif "112 RRQKR $\downarrow F^{117 ", ~ b l o c k e d ~ s y n c y t i u m ~ f o r m a t i o n . ~ H o w e v e r, ~ w e ~ o b s e r v e d ~ t h a t ~ F ~ p r o t e i n s ~ o f ~ t h e ~ v i r u l e n t ~}$ strain F48E9 and avirulent strain LaSota substituted with an identical cleavage motif, " ${ }^{112} R R Q R R \downarrow L{ }^{117 ", ~ i n d u c e d ~}$ extensive and slight syncytium formation, respectively. Accordingly, we hypothesized that the difference in syncytium formation is caused by other regions of the fusion protein.

Results: The exchanged regions between the fusion proteins of two strains, F48E9 and LaSota, showed that the region from amino acid 118-499 plays an important role in modulation of fusogenic activity in transfected cells. Further dissection of this region indicated that replacement of two amino acids (N479D, R486S) in heptad repeat 2 (HR2) of the avirulent fusion protein by the virulent counterpart resulted in fusion promotion. Moreover, the role of these two amino acids in fusion is dependent on the unique Fcs sequence "RRQRR $\downarrow$ L".

Conclusions: Our results demonstrated that two amino acids (D479, S486) of the virulent strain $\mathrm{F}$ protein with this unique Fcs were critical for promoting fusogenic activity, and residue $F$ or $L$ at position 117 did not affect syncytium formation. These findings provide novel insights into fusogenic triggering by the fusion protein and may be useful for designing antiviral peptides.
\end{abstract}

Keywords: Newcastle disease virus, F protein cleavage site, Syncytium formation

Newcastle disease is a highly contagious disease caused by Newcastle disease virus (NDV) that results in severe economic losses in the poultry industry. The NDV belongs to the genus Avulavirus, family Paramyxoviridae and order Mononegavirales. It possesses an enveloped, non-segmented, single-stranded, negative-sense RNA genome, which encode six major proteins-the nucleoprotein $(\mathrm{NP})$, phosphoprotein $(\mathrm{P})$, matrix protein $(\mathrm{M})$, fusion protein $(\mathrm{F})$, hemagglutinin-neuraminidase protein $(\mathrm{HN})$ and large RNA-directed RNA polymerase protein

* Correspondence: yzq8162@163.com; saxiao@nwafu.edu.cn College of Veterinary Medicine, Northwest A\&F University, Yangling, Shaanxi 712100, China
(L) $[1,2]$. NDV infection of susceptible host cells requires two viral glycoproteins, $\mathrm{HN}$ and F. The HN protein mediates attachment to the sialic acid receptor, fusion promotion and release of the virus [3]. The F protein mediates fusion of the virus-cell and cell-cell membranes [4]. Importantly, the F protein cleavage site (Fcs) is believed to be a major determinant of virulence and fusion activity in NDV [5-7]. The F protein is synthesized as an inactive precursor $\left(\mathrm{F}_{0}\right)$, which is cleaved into two disulfide-linked polypeptides, $F_{1}$ and $F_{2}$, by host proteases at the Fcs. This cleavage results in exposure of the fusion peptide at the $\mathrm{N}$ terminus of the $\mathrm{F}_{1}$ subunit, which triggers fusogenic activity. 
NDV strains are generally classified into three pathotypes based on their pathogenicity in chickens: lentogenic (low virulent or avirulent), mesogenic (moderately virulent) and velogenic (highly virulent) $[8,9]$. The Fcs of velogenic and mesogenic strains exhibit a polybasic amino acids motif, "112 $R / K-R-Q-K / R-R \downarrow F^{117 "}$, at the $C$ terminus of the $F_{2}$ protein and a phenylalanine $(\mathrm{F})$ at position 117, which is located at the $\mathrm{N}$ terminus of the $F_{1}$ protein that is cleaved by ubiquitous intracellular proteases. In contrast, the lentogenic Fcs possesses the monobasic amino acid motif " $112 \mathrm{G} / \mathrm{E}-\mathrm{K} / \mathrm{R}-\mathrm{Q}-\mathrm{G} / \mathrm{E}-$ $\mathrm{R} \downarrow \mathrm{L}^{117}$ " at the $C$ terminus of the $F_{2}$ protein and a leucine (L) at position 117 that is cleaved by extracellular trypsin-like proteases restricted to the respiratory and intestinal tract [10]. Alteration of the Fcs affects the fusion activity and virulence of NDV [6, 11-14]. However, some strains and modified viruses containing an identical Fcs motif present varied fusogenic activity [15-17]. In our study, we observed that mutation of the $\mathrm{F}$ proteins of the virulent strain F48E9 and the avirulent strain LaSota to an identical motif, "RRQRR $\downarrow L$ ", altered membrane fusion in transfected cells, suggesting that other regions of the F protein are involved in inducing fusion in addition to the Fcs.

The unique cleavage motif "RRQRR $\downarrow L$ " was found in a natural isolate (99-0868-2) in Australia. Although this isolate had an intracerebral pathogenicity index (ICPI) of 1.38, indicative of a virulent virus, inoculation of the virus into 7-week-old birds demonstrated an avirulent phenotype, suggesting that the motif "RRQRR $\downarrow L "$ is a deduced avirulent Fcs [18]. In our study, we used the $F$ proteins of the virulent strain F48E9 and avirulent strain LaSota as backbones. The F48E9 strain is a standard highly virulent virus in China and possesses a virulent Fcs, "RRQRR $\downarrow F$ ", which induces substantial syncytium formation in the transfected cells. The LaSota strain is a vaccine virus that has an avirulent Fcs, "GRQGR $\downarrow L$ ", which induces slight syncytium formation (Fig. 1a-c). We modified the Fcs of these two strains to the motif "RRQRRL", yielding F48E9-F* (F48-F*) and LaSota-F* (La-F*) (" represents RRQRR $\downarrow$ L) (Fig. 1a). The expression vector pCAGGS was used for all $\mathrm{F}$ and $\mathrm{HN}$ constructs [19]. BHK-21 cells were transfected with the F48- $\mathrm{F}^{*}$ construct and produced significant syncytium formation when cotransfected with F48E9 HN (F48-HN), whereas La-F* caused slight syncytium formation when co-transfected with LaSota HN (La-HN) (Fig. 1b and c). The BHK-21 cells that were transfected with F48-F, F48-F*, La-F or La-F* alone did not produce syncytia (data not shown). The $\mathrm{F}$ and $\mathrm{HN}$ proteins of the strains F48E9 (genotype IX) and LaSota (genotype II) are genetically different, with amino acid identities of 92 and $91 \%$, respectively. To exclude the effect of different $\mathrm{HN}$ proteins on fusogenic activity, we co-transfected the F48- $\mathrm{F}^{*}$ and La- $\mathrm{F}^{*}$ constructs with homologous (F48-HN) and heterologous $\mathrm{HN}(\mathrm{La}-\mathrm{HN})$ proteins, respectively. The results showed that the $\mathrm{F} 48-\mathrm{F}^{*}$ produced extensive syncytia when co-transfected with F48-HN, but larger and more numerous syncytia were observed following cotransfection with La-HN. These findings may be explained by the increased interactions of La-HN with F48- $\mathrm{F}^{*}$ compared to those of F48-HN. The amino acid sequences of La-HN and F48-HN, which show 91\% identity, are different. In addition, La-HN (577 aa) has an additional six amino acids in the $\mathrm{N}$-terminus, which is longer than that of F48-HN (571 aa). These differences in the two HN proteins may affect their interaction with $\mathrm{F} 48-\mathrm{F}^{*}$. However, the La- $\mathrm{F}^{*}$-transfected cells produced very weak syncytia when co-transfected with either La-HN or F48-HN (Fig. 1b and c). The syncytia were quantified by counting the number of nuclei in 40 fusion areas to determine the average syncytia size as previously described [20]. The results indicated that the distinct fusogenic activity was due to the $\mathrm{F}^{*}$ proteins of two strains but not the HN proteins.

To identify which region of the $\mathrm{F}^{*}$ proteins is involved in membrane fusion, we substituted the $F_{2}$ subunit (1-111 aa) of the ectodomain (1-499 aa), transmembrane domain (TM, 500-522 aa) and cytoplasmic tail (CT, 523-553 aa) of F48- $\mathrm{F}^{*}$ with the corresponding regions of $\mathrm{La}^{-\mathrm{F}^{*}}$ in the $\mathrm{F} 48-\mathrm{F}^{*}$ backbone (Fig. 2a). Among them, the F48/La1-111, F48/La500553, F48/La523-553 and F48/La500-522 cells showed extensive syncytia that were similar to those of F48-F* when co-transfected with F48-HN in BHK-21 cells. However, comparatively fewer syncytia were observed with F48/La1-499, F48/La1-522, F48/La118-499, F48/ La118-522 and F48/La118-553 ( $P<0.01)$ (Fig. $2 \mathrm{a}$ and b). The results indicated that the La- $\mathrm{F}^{*} 118-499$ region disrupted the membrane fusion caused by F48-F*. Next, we further replaced the 137-199 (heptad repeat 1 [HR1]), 200-448 and 449-499 (heptad repeat 2 [HR2]) regions of La- $\mathrm{F}^{*}$ with the corresponding regions of F48-F* F48/ La137-448 resulted in the most syncytia among these mutants (Fig. 2c and d). Then, the region 449-499 of F48- $\mathrm{F}^{*}$ was subdivided into two regions of $449-469$ and 470-499. The corresponding mutants F48/La137-448 and F48/La137-469 showed the most syncytia compared to the others $(\mathrm{P}<0.01)$ (Fig. $2 \mathrm{c}$ and $\mathrm{d})$, suggesting that region $470-499$ of F48-F* played an important role in fusion promotion. There are differences in three amino acids in region 470-499 between F48-F and La-F: aspartic acid (D), serine (S) and glycine (G) in F48-F and asparagine (N), arginine (R) and serine (S) in La-F at the positions 479, 486 and 497, respectively. To identify the role of these three amino acids in fusogenic activity, we substituted these residues of La- $\mathrm{F}^{*}$ 


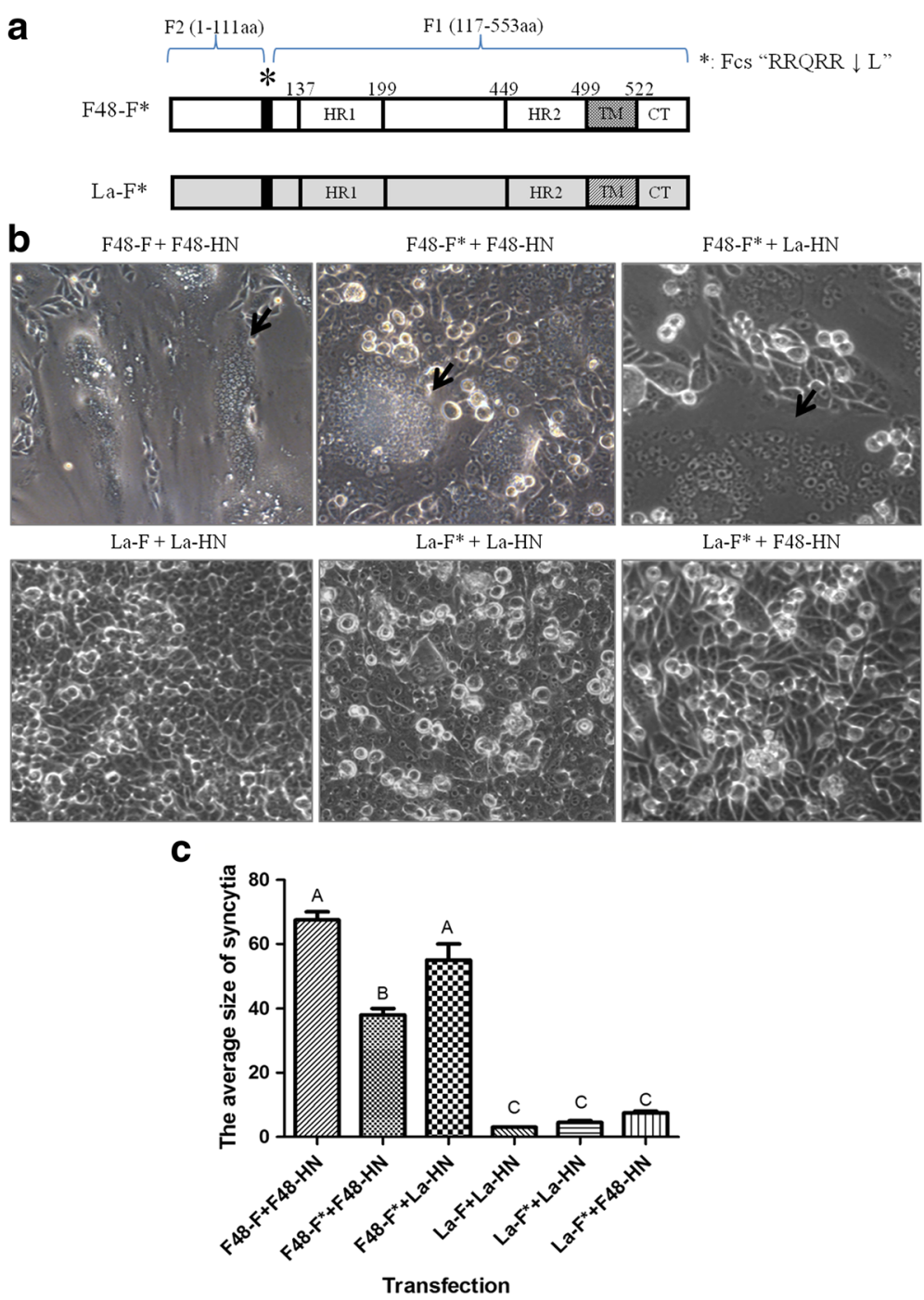

Fig. 1 Difference in syncytium formation induced by F48-F* and La- $F^{*}$ in the transfected BHK-21 cells. a Schematic diagram of the $F$ proteins of the virulent strain F48E9 and avirulent strain LaSota with the cleavage motif "RRQRRL" $\left(^{*}\right)$. b Induction of syncytium formation by co-transfection with the $\mathrm{F}^{*}$ and $\mathrm{HN}$ constructs in BHK-21 cells. At $36 \mathrm{~h}$ post-transfection, monolayers were examined for the presence of syncytia, which were photographed under the microscope. Syncytia are indicated by black arrows. c Quantitative analysis of the syncytia in (b)

individually or dually with those of F48- $\mathrm{F}^{*}$ on the La-F* backbone. Obvious syncytium formation was observed with La-F*(N479D) or La-F*(R486S) during cotransfection with La-HN in BHK-21 cells but not with La-F*(S497G). The double mutant La-F*(N479D, R486S) produced significantly more and larger syncytia than the single mutants La-F*(N479D) and LaF*(R486S) $(P<0.01)$ (Fig. 3a and b). These results demonstrated that the La- $\mathrm{F}^{*}$-specific residues $\mathrm{N} 479$ and R486 played a critical role in fusion disruption.

Using Western blot analysis, we evaluated the cleavage efficiency of the $\mathrm{F}^{*}$ proteins. These $\mathrm{F}^{*}$ mutants were partially cleaved into $F_{1}$ subunit in the transfected cells, but there were no significant differences between them (Fig. 3c). These results indicated that the cleavage efficiency of the $F^{*}$ protein was not correlated with fusion. Generally, cleavage of the NDV F protein is necessary for triggering membrane fusion [21]. However, previous studies showed that the recombinant virulent NDV strain with an avirulent Fcs "GRQGR $\downarrow$ L" did not produce syncytia, although the $\mathrm{F}$ protein was cleaved, suggesting that other factors might be implicated in membrane fusion in addition to Fcs $[14,22]$. We further examined whether the fusion activity induced by the $F^{*}$ mutants was associated with their expression levels on the cell surface. Fluorescence-activated cell sorting (FACS) analysis was performed with an antiNDV polyclonal antibody in the $F^{*}$ constructtransfected cells, and these cells were compared to those with La-F*. The La-F* mutants showed similar 

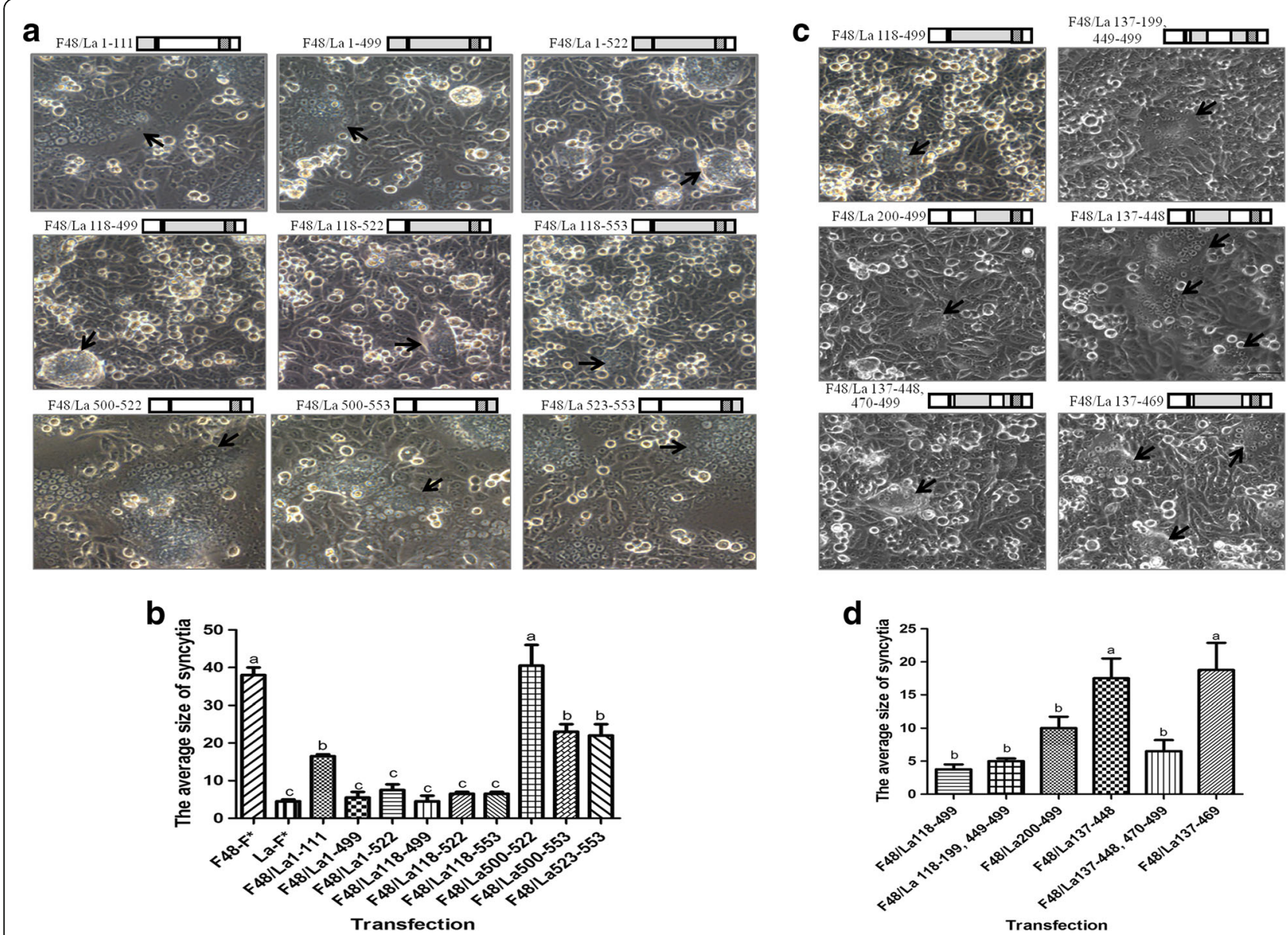

Fig. 2 Effect of different regions of the $\mathrm{F}^{*}$ protein on membrane fusion. a Induction of syncytium formation by different regions between F48-F* and La-F* in BHK-21 cells when co-transfected with F48-HN. Schematic diagram of each construct with substituted regions in F48-F* is shown at the top of each picture. $\mathbf{b}$ Quantitative analysis of syncytia in (a). c Identification of region 449-499 of HR2 in triggering syncytium formation. d Quantitative analysis of the syncytia in (c). Statistical significance is designated with lowercase letters $(P<0.05)$ or capital letters $(P<0.01)$

mean fluorescence intensities to wild type $\mathrm{F}^{*}$ protein, ranging from $91 \%$ to $103 \%$ (Fig. $3 \mathrm{~d}$ ). These results suggested that all the mutant $\mathrm{F}^{*}$ proteins retained their ability to be transported efficiently to the cell surface, and the loss of fusion activity was not due to decreased cell surface expression level. Several reports have shown that regardless of whether the amino acid mutation in the NDV F protein HR2 domain was conservative or nonconservative, it did not significantly inhibit protein surface expression [23, 24].

Generally, virulent F protein with a virulent Fcs can trigger the fusion activity, and those with an avirulent Fcs fail to induce membrane fusion. In our study, the Fcs "RRQRR $\downarrow L$ " is a deduced avirulent Fcs composed of four basic residues with residue $\mathrm{L}$ at position $117\left(\mathrm{~L}^{117}\right)$ of the F protein. The virulent Fcs usually possesses residue $\mathrm{F}$ at position $117\left(\mathrm{~F}^{117}\right)$, which is required for membrane fusion [25]. Therefore, the F48- $\mathrm{F}^{*}$ protein was not expected to induce syncytia. However, we found that the F48- $F^{*}$ protein strongly induced syncytia, whereas the
La- $\mathrm{F}^{*}$ protein slightly induced syncytia. A previous study showed that residue $\mathrm{F}$ mutated to $\mathrm{L}$ at position 117 blocked syncytium formation of strain Beaudette C (BC) with the Fcs "RRQKR $\downarrow$ F" in transfected cells [26]. This is inconsistent with our results that either residue $\mathrm{F}^{117}$ or $\mathrm{L}^{117}$ at the F48-F* enables induction of fusogenic activity. Furthermore, the mutated F48-F with the Fcs "RRQKR $\downarrow L$ " could also induce syncytium formation (data not shown), indicating that the basic residue $\mathrm{K}$ or $\mathrm{R}$ at position 115 of Fcs has no effect on fusion. These findings may be due to the low amino acid identity (92\%) of the F protein between strains F48E9 and BC compared to the strikingly high amino acid identity (98\%) between strains LaSota and BC. This suggests that some amino acids in the $\mathrm{F}$ proteins of different strains affect the membrane fusion in addition to the Fcs.

The F protein of NDV is a type I membrane protein that forms homotrimers during initial protein folding $[2,27,28]$. Region $118-499$ of $F$ contains part of the $F_{1}$ subunit that has sequence elements important in 


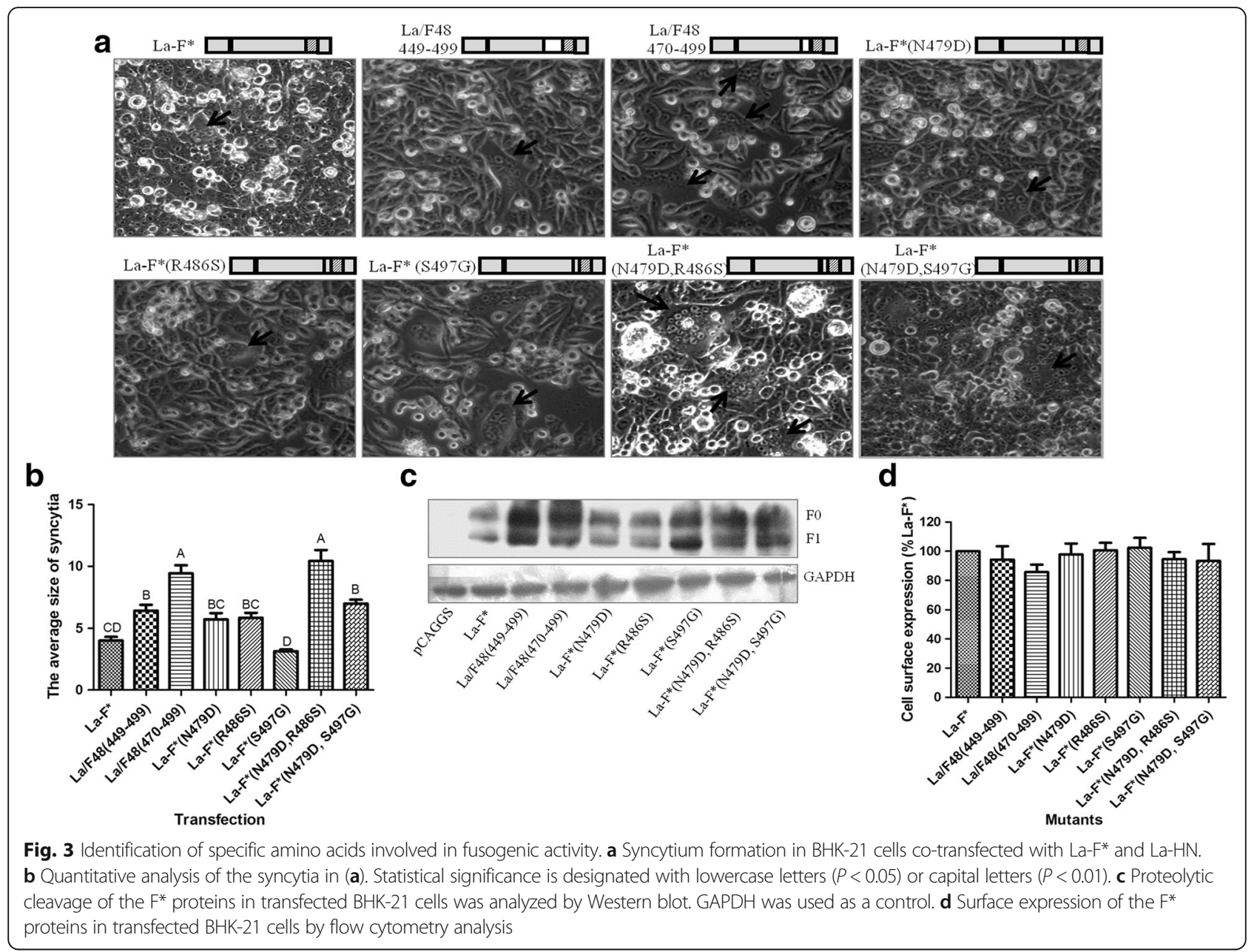

fusion, including HR1 and HR2 [29]. HR1 and HR2 bind each other in an anti-parallel manner as a coiledcoil structure and form the so-called six-helix trimer to drive the merger of viral and target cell membranes [2, 30-32]. The coiled-coil structure is encoded by a seven-residue repeat denoted $[\mathrm{abcdefg}]_{\mathrm{n}}$, which typically has hydrophobic residues at a and d and polar/ charged residues at e and $\mathrm{g}$. The amino acid residues at $\mathrm{c}, \mathrm{e}$, and $\mathrm{f}$ are located on the outside region of the coiled coil and would not have any effect on the overall structure [33, 34]. Using LearnCoil-VMF analysis [35, 36], we found that N479D and R486S at position $f$ of the coiled-coil structure promoted fusion activity in La- $\mathrm{F}^{*}$, and S497G at position c did not. A previous report showed that the HR1 and HR2 derived from a combination of the F48E9 and avirulent Changchun strains yielded heterotrimer formation, which is required for membrane fusion, despite nine amino acid differences at the positions 145; 139, 461 and 497; 456; 451, 479 and 486; and 192 located at the b, c, e, $\mathrm{f}$, and $\mathrm{g}$ sites of the coiled-coil structure [33]. The HR2 of La- $\mathrm{F}^{*}$ with the single mutant N479D or R486S or the double mutant (N479D, R486S) may form more stable six-helix bundle trimers with HR1 to promote membrane fusion.

Finally, we examined the role of two amino acids at positions 479 and 486 of F48-F*, wild-type F48-F and La-F in fusogenic activity. These two residues in the F48-F* were mutated to $479 \mathrm{~N}$ and $486 \mathrm{R}$ of La-F*. The results showed that the mutant F48-F*(D479N, S486R) did not affect membrane fusion compared to $F 48-F^{*}$ in transfected BHK-21 cells. Furthermore, the mutants F48-F (D479N, S486R) and La-F (N479D, R486S) did not significantly change the fusogenic activity compared to wild-type F48-F and La-F (data not shown). The results demonstrated that the two mutations affecting fusogenic activity depended on the unique motif "RRQRR $\downarrow L$ ". In addition, although the single mutations La-F*(N479D) and La-F*(R486S) increased membrane fusion activity, their fusion index did not reach that induced by F48- $\mathrm{F}^{*}$. However, the fusion level caused by a substitution construct $\mathrm{La}-\mathrm{F}^{*} / \mathrm{F} 48(118-499)$ was similar to that of F48-F* (data not shown), suggesting that except for residues D479 and S486, other amino acids in the 118-499 region of F48- $\mathrm{F}^{*}$ might act synergistically to 
achieve the high level of fusion induced by La-F*. A recent study reported that the mutation N403D in the F protein of mesogenic strain BC with the avirulent FCS "GRQGR $\downarrow L$ " substantially reduced the fusion activity [17]. Another report showed that the single mutation T458D or G459D in the HR2 region of the F protein in the virulent G7 strain enhanced cell fusion [24]. Taken together, these data suggest that in addition to Fcs, the amino acids of the F protein contribute to fusogenic activity with conditional limitations, including strain, virulence, and cleavage motif sequence. Future studies should examine the effects of the two amino acids at positions 479 and 486 with the unique Fcs motif on virological characteristics by using recombinant virulent and avirulent viruses.

\section{Abbreviations}

aa: Amino acid; FACS: Fluorescence-activated cell sorting;

GAPDH: Glyceraldehyde-3-phosphate dehydrogenase; HR1: Heptad repeat 1; HR2: Heptad repeat 2; ICPI: Intracerebral pathogenicity index; NDV: Newcastle disease

\section{Acknowledgements}

Not applicable.

\section{Funding}

This work was supported by the National Natural Science Fundation of China (31,572,533 to SX, 31,572,538 to ZY) and the Faculty Support Fund of the Northwest A\&F University (Z111021401). The funding agency had no role in study design, data collection and analysis, decision to publish, or preparation of the manuscript.

\section{Availability of data and materials}

The datasets used and analyzed in the current study are available from the corresponding author upon reasonable request.

\section{Authors' contributions}

YW, SX designed the experiments. YW, YB and WY performed experiments. YW, NW, WW and QW analyzed the data, YW, SX, XW, SZ and ZY wrote and edited the manuscript. All authors read and approved the final manuscript.

\section{Ethics approval and consent to participate}

Not applicable

\section{Consent for publication}

Not applicable

\section{Competing interests}

The authors declare that they have no competing interests.

\section{Publisher's Note}

Springer Nature remains neutral with regard to jurisdictional claims in published maps and institutional affiliations.

Received: 24 July 2017 Accepted: 17 September 2017 Published online: 25 September 2017

\section{References}

1. Alexander DJ. Newcastle disease virus and other avian paramyxoviruses. In: Swayne DE, Glisson JR, Jackwood MW, Pearson JE, Reed WM, editors. A laboratory manual for the isolation and identification of avian pathogens. 4th ed. Keenett Square: American Association of Avian Pathologists, Inc:; 1998. p. 156-63.

2. Lamb RA, Parks GD. Paramyxoviridae: the viruses and their replication. In: Knipe DM, Howley PM, editors. Fields virology. 5th ed. Philadelphia: Wolters Kluwer-Lippincott Williams \& Wilkins; 2007. p. 1449-96.
3. Mirza AM, Deng R, lorio RM. Site-directed mutagenesis of a conserved hexapeptide in the paramyxovirus hemagglutinin-neuraminidase glycoprotein: effects on antigenic structure and function. J Virol. 1994;68(8):5093-9.

4. Lamb RA, Kolakofsky D. Paramyxoviridae: the viruses and their replication. In: Knipe DM, Howley PM, editors. Fundamental virology. 4th ed. Philadelphia: Lippincott Williams \& Wilkins; 2001. p. 689-724.

5. Nagai Y, Klenk HD, Rott R. Proteolytic cleavage of the viral glycoproteins and its significance for the virulence of Newcastle disease virus. Virology. 1976;72(2):494-508.

6. Peeters BPH, Leeuw OSD, Koch G, Gielkens ALJ. Rescue of Newcastle Disease Virus from cloned cDNA: evidence that cleavability of the fusion protein is a major determinant for virulence. J Virol. 1999;73(6):5001-9.

7. Panda A, Huang Z, Elankumaran S, Rockemann DD, Samal SK. Role of fusion protein cleavage site in the virulence of Newcastle disease virus. Microb Pathog. 2004;36(1):1-10.

8. Alexander DJ. Newcastle disease. In: Purchase HG, Arp LH, Domermuth CH, Pearson JE, editors. A laboratory manual for the isolation and identification of avian pathogens. 3rd ed. Dubuque: The American Association of Avian Pathologists, Kendall//Hunt Publishing Company; 1989. p. 114-20.

9. Dortmans JC, Koch G, Rottier PJ, Peeters BP. Virulence of newcastle disease virus: what is known so far? Vet Res. 2011;42:122.

10. Collins M, Strong I, Alexander D. Evaluation of the molecular basis of pathogenicity of the variant Newcastle disease viruses termed "pigeon PMV1 viruses". Arch Virol. 1994;134(3):403-11.

11. Li Z, Sergel T, Razvi E, Morrison T. Effect of cleavage mutants on syncytium formation directed by the wild-type fusion protein of Newcastle disease virus. J Virol. 1998;72(5):3789-95.

12. de Leeuw OS, Hartog L, Koch G, Peeters BP. Effect of fusion protein cleavage site mutations on virulence of Newcastle disease virus: nonvirulent cleavage site mutants revert to virulence after one passage in chicken brain. J Gen Virol. 2003;84(Pt 2):475-84.

13. Samal S, Kumar S, Khattar SK, Samal SK. A single amino acid change, Q114R, in the cleavage-site sequence of Newcastle disease virus fusion protein attenuates viral replication and pathogenicity. J Gen Virol. 2011;92(Pt 10): 2333-8.

14. Xiao S, Baibaswata N, Arthur S, Anandan P, Prajitno TY, Bharoto EE, et al. Generation by reverse genetics of an effective, stable, live-attenuated Newcastle disease virus vaccine based on a currently circulating, highly virulent Indonesian strain. PLoS One. 2012;7(12):e52751.

15. Paldurai A, Kim SH, Nayak B, Xiao S, Shive H, Collins PL, et al. Evaluation of the contributions of individual viral genes to newcastle disease virus virulence and pathogenesis. J Virol. 2014;88(15):8579-96.

16. Heiden S, Grund C, Röder A, Granzow H, Kühnel D, Mettenleiter TC, et al. Different regions of the newcastle disease virus fusion protein modulate pathogenicity. PLoS One. 2014;9(12):e113344.

17. Kim SH, Xiao S, Collins PL, Samal SK. LaSota F cleavage motif-mediated fusion activity is affected by other regions of $\mathrm{F}$ protein from different genotype Newcastle disease virus in a Chimeric virus: implication for virulence attenuation. J Gen Virol. 2016;97(6):1-8.

18. Kattenbelt JA, Stevens MP, Gould AR. Sequence variation in the Newcastle disease virus genome. Virus Res. 2006;116(1-2):168-84.

19. Niwa H, Yamamura K, Miyazaki J. Efficient selection for high-expression transfectants by a novel eukaryotic vector. Gene. 1991;108:193-200.

20. Sergel T, Mcginnes LW, Peeples ME, Morrison TG. The attachment function of the Newcastle disease virus hemagglutinin-neuraminidase protein can be separated from fusion promotion by mutation. Virology. 1993;193(2):717-26.

21. Nagai $\mathrm{Y}$, Ogura $\mathrm{H}$, Klenk $\mathrm{H}$. Studies on the assembly of the envelope of Newcastle disease virus. Virology. 1976;69(2):523-38.

22. Kim SH, Chen Z, Yoshida A, Paldurai A, Xiao S, Samal SK. Evaluation of fusion protein cleavage site sequences of Newcastle disease virus in genotype matched vaccines. PLoS One. 2017;12(3):e0173965.

23. Mcginnes LW, Sergel T, Chen H, Hamo L, Schwertz S, Li D, et al. Mutational analysis of the membrane proximal heptad repeat of the newcastle disease virus fusion protein. Virology. 2001;289(2):343-52.

24. Ji Y, Liu T, Jia Y, Liu B, Yu Q, Cui X, et al. Two single mutations in the fusion protein of Newcastle disease virus confer hemagglutinin-neuraminidase independent fusion promotion and attenuate the pathogenicity in chickens. Virology. 2017;509:146

25. Pritzer E, Kuroda K, Garten W, Nagai Y, Klenk HD. A host range mutant of Newcastle disease virus with an altered cleavage site for proteolytic activation of the F protein. Virus Res. 1990;15(3):237-42. 
26. Morrison T, Mcquain C, Sergel T, Mcginnes L, Reitter J. The role of the amino terminus of $\mathrm{F} 1$ of the Newcastle disease virus fusion protein in cleavage and fusion. Virology. 1993;193(2):997-1000.

27. Russell $R$, Paterson RG, Lamb RA. Studies with cross-linking reagents on the Oligomeric form of the Paramyxovirus fusion protein. Virology. 1994;199(1):160-8.

28. Morrison TG. Structure and function of a paramyxovirus fusion protein. Biochim Biophys Acta. 2003;1614(1):73-84.

29. Asano $K$, Asano $A$. Why is a specific amino acid sequence of $F$ glycoprotein required for the membrane fusion reaction between envelope of HVJ (Sendai virus) and target cell membranes? Biochem Int. 1985;10(1):115-22.

30. Eckert DM, Kim PS. Mechanisms of viral membrane fusion and its inhibition. Annu Rev Biochem. 2001;70:777-810.

31. Sergelgermano T, Mcquain C, Morrison T. Mutations in the fusion peptide and heptad repeat regions of the Newcastle disease virus fusion protein block fusion. J Virol. 1994;68(11):7654-8.

32. Reitter $\mathrm{JN}$, Sergel $\mathrm{T}$, Morrison TG. Mutational analysis of the leucine zipper motif in the Newcastle disease virus fusion protein. J Virol. 1995;69(10): 5995-6004.

33. Yu M, Wang E, Liu Y, Cao D, Jin N, Zhang CW, et al. Six-helix bundle assembly and characterization of heptad repeat regions from the $\mathrm{F}$ protein of Newcastle disease virus. J Gen Virol. 2002;83(Pt 3):623-9.

34. Grigoryan G, Keating AE. Structural specificity in coiled-coil interactions. Curr Opin Struct Biol. 2008;18(4):477-83.

35. Singh M, Berger B, Kim PS. LearnCoil-VMF: computational evidence for coiled-coil-like motifs in many viral membrane-fusion proteins. J Mol Biol. 1999;290(5):1031-41.

36. Xu Y, Gao S, Cole DK, Zhu J, Su N, Wang H, et al. Basis for fusion inhibition by peptides: analysis of the heptad repeat regions of the fusion proteins from Nipah and Hendra viruses, newly emergent zoonotic paramyxoviruses. Biochem Biophys Res Commun. 2004;315(3):664-70.

\section{Submit your next manuscript to BioMed Central and we will help you at every step:}

- We accept pre-submission inquiries

- Our selector tool helps you to find the most relevant journal

- We provide round the clock customer support

- Convenient online submission

- Thorough peer review

- Inclusion in PubMed and all major indexing services

- Maximum visibility for your research

Submit your manuscript at www.biomedcentral.com/submit

) Biomed Central 